\title{
Evaluation of Concordance Between Histopathological, Radiological and Biomolecular Variables in Breast Cancer Neoadjuvant Treatment
}

\author{
ORESTE CLAUDIO BUONOMO ${ }^{1}$, ANDREA GRASSO ${ }^{1}$, CHIARA ADRIANA PISTOLESE ${ }^{2}$, \\ LUCIA ANEMONA ${ }^{3}$, ILARIA PORTARENA ${ }^{4}$, ROSARIA MEUCCI ${ }^{2}$, \\ LJUBA MORANDO $^{1}$, CAMILLA DEIANA $^{1}$, MARCO MATERAZZO $^{1}$ and GIANLUCA VANNI ${ }^{1}$ \\ ${ }^{1}$ Breast Unit-Department of Surgical Science, Policlinico Tor Vergata (PTV) University, Rome, Italy; \\ ${ }^{2}$ Department of Diagnostic Imaging and Interventional Radiology, \\ Molecular Imaging and Radiotherapy, Policlinico Tor Vergata (PTV) University, Rome, Italy; \\ ${ }^{3}$ Anatomic Pathology, Department of Experimental Medicine, Policlinico Tor Vergata (PTV) University, Rome, Italy; \\ ${ }^{4}$ Department of Oncology, Policlinico Tor Vergata (PTV) University, Rome, Italy
}

\begin{abstract}
Background/Aim: Neoadjuvant chemotherapy (NAC) for breast cancer $(B C)$ is the gold standard treatment for locally advanced tumors (LABC) that aims at achieving a complete pathological response ( $p C R$ ). Studies have been conducted to evaluate and identify te concordance between radiological, histopathological and biological variables of $B C$ and final response to therapy, verified by definitive histological examination after surgery. Patients and Methods: Ninety-five BC patients were examined and subjected to NAC. Immunohistochemical markers including oestrogen-receptor (ER), progesteronereceptor (PR), Ki67 index, and human epidermal growth factor receptor 2 (HER2) score were examined before and after neoadjuvant treatment. Results: Younger age and a significant decrease in ER expression were associated with better prognosis. Triple Negative (TN) and Her2-type breast cancers benefited most from neoadjuvant chemotherapy with higher frequency of $p C R$. Conclusion: HER2-type and TN BC are correlated with best response to NAC. A statistically significant correlation between radiological images and definitive histological examination was not observed.
\end{abstract}

This article is freely accessible online.

Correspondence to: Andrea Grasso, Breast Unit - Department of Surgical Science, Policlinico Tor Vergata (PTV) University, Viale Oxford 81, 00133 Rome, Italy. Tel: +39 3395685883, e-mail: andry993@tiscali.it

Key Words: Breast cancer, neoadjuvant chemotherapy, complete pathological response, MRI accuracy, histological examination.
Neoadjuvant chemotherapy (NAC) is now considered the gold standard treatment for advanced breast cancer (BC) (1) and inflammatory carcinoma (2) to reduce the extent of subsequent surgical treatment $(3,4)$. Up to $40 \%$ of patients undergoing NAC were able to benefit from conservative treatments with oncoplastic techniques through radio-guided localization lesion and peripheral nerve block (5-8), due to downsizing and downstaging yielded by NAC. Important aspects in the use of NAC concern the early introduction of systemic therapy and the in vivo assessment of tumor response (9). Randomized studies have not actually shown a clear increase in the overall survival of patients following neoadjuvant therapy, therefore the pre-operative and post-operative systemic strategy appear to be equivalent (10-15). Patients with total absence of BC after NAC, namely pathological complete response (pCR), demonstrate an advantage in overall survival (OS) and eventsfree survival (EFS) as recently confirmed by a metanalysis study presented at the San Antonio Breast Cancer Symposium in 2018 (16-18), where Spring et al. showed that patients who obtained a pCR had reduced relapse probability of $69 \%$ than their counterparts with residual disease $[\mathrm{HR}=0.31,95 \%$ probability intervals $(\mathrm{PI})=0,24-39]$ (16). The importance of NAC has been suggested by oncological clinical studies; in fact, pCR rate is routinely used as a surrogate outcome related to OS and EFS in new drug development in biological and immunological therapy $(19,20)$. Furthermore, different gains of OS and EFS after pCR seem to correlate to different BC subtypes (21). However, only a small percentage of patients obtain a pCR and a statistically significant gain on diseasefree survival (DFS) and/or OS.

Recent studies have indicated that predictive molecular biomarkers may optimize the selection of effective therapies in NAC candidate patients, thus reducing costs and side effects in BC and oncology treatments in general (22-25). 
The present study aimed to evaluate and identify a concordance between radiological, histopathological and biological variables of the neoplasia, assessed before and after neoadjuvant chemotherapy treatment, and the final response to therapy, verified by definitive histological examination after surgery. Consequently, having established a correlation between them, these characteristics could be used to define a more personalized therapeutic strategy for the patient by selecting specific cases that would yield the benefit of less invasive surgical treatments, such as conservative surgical procedures $(24,26-29)$ (quadrantectomy or glandular resection) or oncoplastic surgery $(6,30,31)$.

\section{Patients and Methods}

Our retrospective monocentric study examined ninety-five patients, from 2005 to 2019 , having mammary neoplasia as a first diagnosis, undergoing neoadjuvant chemotherapy and, subsequently, surgery at the Tor Vergata Hospital in Rome. All patients were evaluated by a multidisciplinary team composed of an oncoplastic breast surgeon, a radiologist, an anatomopathologist, an oncologist, a radiotherapist and a specialized nurse.

All patients underwent magnetic resonance imaging (MRI) with a contrast medium and a biopsy using a mammotome or tru-cut method to determine the histology and biological structure of the tumor. In particular, hormonal receptor status of ER and PR, Ki67 and HER2 overexpression were evaluated. On the basis of the immunohistochemical characteristics, the tumors were subsequently classified into luminal and non-luminal categories. Additional eligibility criteria included a Performance Status assessed on an ECOG scale of $0 / 1$, haemoglobin levels $>12 \mathrm{~g} / \mathrm{dl}$, white blood cells $>4.0 \times 10^{9} / 1$ and platelets $>100 \times 10^{9} / 1$. All patients had also adequate renal, hepatic and cardiac function indicated by an Ejection Fraction (FE) $>50 \%$.

For the clinical evaluation of chemotherapy response, a mammary MRI was performed during and at the end of the treatment; a physical examination was also performed on the same day of the chemotherapy session. At the end of the neoadjuvant therapy, the patients underwent surgery and, subsequently, where necessary, adjuvant radiotherapy treatment. At the time of diagnosis, the patients tested had an average age of 51.9 years. The general admission criteria were successful neo-adjuvant chemotherapy, surgical treatment, and subsequent follow-up at the departments of General Surgery C, Medical Oncology, Pathological Anatomy, and Radiology at the Tor Vergata hospital.

The entire patient population was divided into two groups: the first consisting of seventy patients, who had a residual tumor or progression of the disease and did not reach the complete pathological response; the second consisting of twenty-five women who achieved pCR, confirmed by definitive histology indicating the absence of neoplasia.

At the end of the last chemotherapy cycle, all patients underwent mastectomy or quadrantectomy as deemed required on the basis of the last MRI. The choice of the surgical procedure was made during a multidisciplinary meeting, and was based on patient's preference, scientific evidence at the time of diagnosis, and the therapeutic program.

If possible, an oncoplastic conservative surgical approach was adopted on all patients following neoadjuvant chemotherapy, as required on the basis of the extemporaneous, definitive, and radical histological examination (no Ink on Tumor).

In the case of non-palpable neoplasia susceptible to conservative surgical treatment, the localization of the lesion was achieved by wire-guided localization or radio-guided occult lesion localization according to the surgeon's preference $(8,32)$. Either ultrasound or mammography were used for guidance in performing the surgical procedure based on the specific clinical case and preference of the breast radiologist. If the preoperative examinations indicated the presence of microcalcifications, specimen mammography was used to verify the radicality of the surgical procedure carried out.

Furthermore, the oncological radicality was assessed by studying the margins by extemporaneous histological examination using haematoxylin-eosin staining.

Patients diagnosed with infiltrating or micro-infiltrating neoplasia underwent sentinel node biopsy or axillary dissection, depending on the patient's clinical characteristics, the clinical stage of the regional lymph nodes $(\mathrm{cN})$, the clinical stage of the tumor $(\mathrm{cT})$ and other clinical-instrumental parameters.

The diagnosis of infiltrating carcinoma was carried out by microhistological biopsy (VAB or Mammotome procedure), eco-guided diagnostic needle biopsy, performed on small portions of tissue taken from a nodule or a suspected area.

Localisation of the sentinel lymph node, where necessary, was performed through Segmental Lymphatic Scintigraphy using ${ }^{99 \mathrm{~m}} \mathrm{Tc}$ Albumin nanocolloid by Gamma Detection System (33).

Statistical analysis. Patients and tumor characteristics were analysed by Student's $t$-test for quantitative variables and the Pearson Chisquare test for qualitative or categorical variables. In the case of statistically significant values, the odds ratio (OR) was calculated based on the contingency tables (Chi square test), to evaluate the strength of the statistical association between the variables considered.

Statistical analysis was performed using SPSS Software (IBM SPSS V.20, Chicago, IL, USA).

\section{Results}

Age at diagnosis. Considering the two populations examined, statistically significant differences emerged regarding the average age at the time of diagnosis $(p=0.018)$, which demonstrated a gap of about 5 years among those who obtained pCR (47.96 years), compared to the second group of patients who instead had no pCR (53.39 years) (34).

Immunohistochemistry. The immunohistochemical histological examination showed significant correlations with the achievement of pCR. The mean expression value of the oestrogen receptor (ER) was much lower among the pCR+ patients compared to pCR-: $63 \%$ vs. $46.84 \% \quad(p=0.031)$, respectively (35) (Table I).

Immunophenotype. Taking into consideration each different tumour subtype, it was found that patients with biological features of Luminal B - represent the highest percentage in both the total number of patients, 41 out of $95(43.1 \%)$, and those with pCR, which were 11 out of $25(44 \%)(p=0.043)$ 
Buonomo et al: Histopathological, Radiological and Biomolecular Variables in Breast Cancer Neoadjuvant Treatment

Table I. Expression of ER, $P R$ and Ki-67 in tumors in $p C R+$ and $p C R-$.

\begin{tabular}{lccc}
\hline & PCR+ & PCR- & $p$-Value \\
\hline ER & $46 \%$ & $63 \%$ & $0.031^{*}$ \\
PR & $29 \%$ & $36 \%$ & $>0.05$ \\
KI-67 & $42 \%$ & $35 \%$ & $>0.05$ \\
\hline
\end{tabular}

ER: Estrogen receptor; PR: progesterone receptor; Ki-67: proliferative activity; pCR: complete pathological response.

Table II. Subdivision of the sample according to the immunological subtype in $p C R+$ and $p C R-$ groups.

\begin{tabular}{lccc}
\hline Molecular subtype & $\begin{array}{c}\mathrm{pCR}+ \\
\mathrm{n}(\%)\end{array}$ & $\begin{array}{l}\mathrm{pCR}- \\
\mathrm{n}(\%)\end{array}$ & $\begin{array}{c}\text { Total } \\
\mathrm{n}(\%)\end{array}$ \\
\hline LUM A & $2(8 \%)$ & $12(17.1 \%)$ & $14(14.7 \%)$ \\
LUM B- & $11(44 \%)$ & $30(42.9 \%)$ & $41(43.2 \%)$ \\
LUM B+ & $5(20 \%)$ & $22(31.4 \%)$ & $27(28.4 \%)$ \\
HER 2 type & $4(16 \%)$ & $1(1.4 \%)$ & $5(5.3 \%)$ \\
Triple negative & $3(12 \%)$ & $5(7.2 \%)$ & $8(8.4 \%)$ \\
Total & $25(100 \%)$ & $70(100 \%)$ & $95(100 \%)$ \\
\hline
\end{tabular}

Lum A: Luminal A; Lum B-: luminal B-; Lum B+: luminal B+; HER2: human epidermal growth factor receptor 2 ; pCR: complete pathological response.

(Table II). It is also encouraging that the analysis concerning the HER2 Type and the TN BC confirmed the data presented in the literature, which indicate that these two subtypes benefit most from NAC with a remarkable sensitivity compared to the others $(34,36)$ (Table II). Although the HER2 Type represents a small percentage of patients studied, i.e. 5 (5.2\% of the total), 4 of these achieved pCR $(80 \%$ of the total HER2 Type, $16 \%$ of the total cases with pCR). For the TN group, 3 of the 8 cases obtained pCR (37\% of the total with TNBC, and $12 \%$ of the total cases with pCR) (Table II).

Subsequently, the sample was subdivided in luminal (Lum) and non-luminal (NLum) to highlight the different response to NAC based on the positivity or not of hormone receptors.

Eighty-two patients belonged to the Lum group (86.3\%), while 13 to the NLum group (13.6\%) (Table III). Of great importance are the data showing that among the Nlum, 7 patients obtained pCR after surgery, which is more than half of the patients of this group (Table III).

Index $c T$. A greater frequency of cT2 (neoplasia with a size between $2 \mathrm{~cm}$ and $5 \mathrm{~cm}$ ) was found in this sample corresponding to $52.6 \%$; this group also includes the highest percentage of patients, 16 out of $25(64 \%)$, who then obtained pCR.
Table III. Subdivision of patients according to the Lum and Nlum groups.

\begin{tabular}{lccc}
\hline & $\begin{array}{c}\mathrm{pCR}+ \\
\mathrm{n}(\%)\end{array}$ & $\begin{array}{c}\mathrm{pCR}- \\
\mathrm{n}(\%)\end{array}$ & $\begin{array}{c}\text { Total } \\
\mathrm{n}(\%)\end{array}$ \\
\hline LUM & $18(72 \%)$ & $64(91.4 \%)$ & $82(86.3 \%)$ \\
NLUM & $7(28 \%)$ & $6(8.6 \%)$ & $13(13.7 \%)$ \\
Total & $25(100 \%)$ & $70(100 \%)$ & $95(100 \%)$ \\
\hline
\end{tabular}

Lum: Luminal; NLum: non luminal.

Table IV. Histological subdivision in the $p C R+$ and $p C R-$.

\begin{tabular}{lccr}
\hline Histology type & $\begin{array}{c}\text { pCR+ } \\
\mathrm{n}(\%)\end{array}$ & $\begin{array}{c}\mathrm{pCR}- \\
\mathrm{n}(\%)\end{array}$ & $\begin{array}{c}\text { Total } \\
\mathrm{n}\end{array}$ \\
\hline IDC & $14(56 \%)$ & $43(61.4 \%)$ & 57 \\
ILC & $0(0 \%)$ & $5(7.1 \%)$ & 5 \\
INSC & $9(36 \%)$ & $21(30 \%)$ & 30 \\
IUC & $2(8 \%)$ & $1(1.5 \%)$ & 3 \\
Total & $25(100 \%)$ & $70(100 \%)$ & 95 \\
\hline
\end{tabular}

IDC: Invasive ductal carcinoma; ILC: invasive lobular carcinoma; INSC: invasive non specific carcinoma; IUC: invasive undifferentiated carcinoma.

By calculating the dimensions of the larger diameter at the time of diagnosis, no statistically significant value was reached regarding the correlation between the initial dimensions of the neoplasia and the final pCR. The pCR+ group had an average diameter of $38.63 \mathrm{~mm}$ while that of the pCR-group was $39.95 \mathrm{~mm}$.

Histology. The comparison between the initial histological examination and pCR did not yield any statistical significance (Table IV).

RECIST criteria. Complete response was found in only 14 patients, in which remission of the disease was no longer visible through MRI with contrast medium. Of these, 5 obtained to pCR, while 9 still had residual tumor. Conversely, 57 of the total number of patients belonged to the partial response (PR) group, characterized by a considerable reduction of disease $(>30 \%)$, but not its complete disappearance on MRI. Of these 57 patients, 17 obtained pCR in the definitive histological examination, while 40 did not reach pCR (Table V).

EFS and OS. Given an average follow-up period of 5.3 years, we highlighted how the achievement of pCR has been an endpoint of primary importance because it was associated 
with a higher percentage of EFS (37) compared to those who did not reach EFS $76.7 \%$ vs. $72.8 \%$ (Table VI).

The same result was also observed in the OS analysis, in which the percentage was always higher in the pCR+ population (37), 96.1\% against $88.4 \%$ compared to pCR-, which still presented with neoplasia in the final histological examination after surgery (Table VI). Analysis of EFS and OS scores based on the Lum and NLum subdivision of mammary carcinomas demonstrated that in luminal subjects the percentages of EFS and OS did not differ significantly with respect to pCR achievement, i.e. EFS $72 \%$ vs. $75 \%$; OS $94 \%$ vs. $90 \%$ (Table VI). The NLum group presented a different situation: the percentages of EFS and OS with respect to pCR were significantly higher; $86 \%$ vs. $50 \%$ and $100 \%$ vs. $66 \%$, respectively.

\section{Discussion}

Our study demonstrated that age can be a predictor of response to therapy because the average age of patients who underwent pCR was 5 years smaller than those who had residual neoplasia still visible upon the final histological examination. Literature also shows that the age at onset of neoplasia constitutes an unfavourable prognostic factor (34). The ER expression is another factor which was analysed. A lower ER value was statistically associated with a better response to chemotherapy (35). HER2 Type and TN neoplasms benefit most from NAC with a clearly higher frequency of pCR $(34,38)$. The HER2 types were the subtypes with the highest $\mathrm{pCR}$ rates of $80 \%$. There were also significant differences between Lum and NLum subjects in their response to NAC: pCR was reached in $21 \%$ of Lum patients and $53 \%$ of NLum patients. Data, therefore, confirmed that the absolute indications for women with breast cancer are over-expression of HER2, high Ki67 score, and negative hormone receptors. Our study did not yield a statistically valid predictive value that could correlate the complete response, on the basis of an MRI performed at the end of chemotherapy, and the pCR. Therefore, histological examination of the biopsies' sample at the end of NAC is essential before subsequent surgical treatment. In our opinion, either molecular or nuclear dedicated breast imaging could improve the sensibility and complete surgical resection of any residual tumors (39-41). Additionally, EFS and OS indices have been calculated and proven to be greater, as also reported in literature, in those patients who obtained pCR.

In conclusion, it would be plausible to underscore that tumors belonging to the HER2 Type class and the TN BC are those most sensitive and with the best response to NAC, with statistically higher pCR rates than luminal. A statistically significant agreement between radiological images and definitive histological examination was not observed. In fact, no evidence was found from our study that would allow an association to be made between the disappearance of tumors
Table V. Subdivision according to RECIST criteria of $p C R+$ and $p C R-$ groups.

\begin{tabular}{lccc}
\hline Recist criteria & $\begin{array}{l}\text { pCR+ } \\
\mathrm{n}(\%)\end{array}$ & $\begin{array}{l}\text { pCR- } \\
\mathrm{n}(\%)\end{array}$ & $\begin{array}{c}\text { Total } \\
\mathrm{n}(\%)\end{array}$ \\
\hline $\mathrm{CR}$ & $5(8 \%)$ & $9(1.9 \%)$ & $14(14.7 \%)$ \\
$\mathrm{PR}$ & $17(56 \%)$ & $40(57.1 \%)$ & $57(60 \%)$ \\
$\mathrm{SD}$ & $2(28 \%)$ & $19(27.1 \%)$ & $21(22.1 \%)$ \\
$\mathrm{PD}$ & $1(8 \%)$ & $2(2.9 \%)$ & $3(3.2 \%)$ \\
Total & $25(100 \%)$ & $70(100 \%)$ & $95(100 \%)$ \\
\hline
\end{tabular}

CR: Complete response; PR: partial response; SD: stable disease; PD: progressive disease.

Table VI. Events Free Survival and Overall survival values in the $p C R+$ and $p C R-$ groups.

\begin{tabular}{lll}
\hline & $\begin{array}{c}\mathrm{pCR}+ \\
(\%)\end{array}$ & $\begin{array}{c}\mathrm{pCR}- \\
(\%)\end{array}$ \\
\hline EFS & $76.6 \%$ & $72.8 \%$ \\
OS & $96 \%$ & $88 \%$ \\
\hline
\end{tabular}

EFS: Events free survival; OS: overall survival.

Table VII. Subdivision of $p C R+$ and $p C R-$ groups into Lum and NLum for the evaluation of EFS Ed OS.

\begin{tabular}{lcccc}
\hline & \multicolumn{2}{c}{ LUM } & \multicolumn{2}{c}{ NLUM } \\
\cline { 2 - 5 } & $\begin{array}{c}\mathrm{pCR}+ \\
(\%)\end{array}$ & $\begin{array}{c}\mathrm{pCR}- \\
(\%)\end{array}$ & $\begin{array}{c}\mathrm{pCR}+ \\
(\%)\end{array}$ & $\begin{array}{c}\mathrm{pCR}- \\
(\%)\end{array}$ \\
\hline $\mathrm{EFS}$ & $72.2 \%$ & $75 \%$ & $86.6 \%$ & $50 \%$ \\
$\mathrm{OS}$ & $94.4 \%$ & $90.6 \%$ & $100 \%$ & $66.6 \%$ \\
\hline
\end{tabular}

EFS: Events free survival; OS: overall survival; Lum: luminal; Nlum: non luminal.

in preoperative MRI and subsequent pCR. The results obtained from the follow-up of the patients confirmed that a higher percentage of patients reached $\mathrm{pCR}$ with respect to both EFS and OS.

\section{Conflicts of Interest}

The Authors declare no conflicts of interest in regard to this study.

\section{Authors' Contributions}

Study conception and design: Buonomo Oreste Claudio, Grasso Andrea; Acquisition of data: Materazzo Marco, Chiara Adriana 
Pistolese; Analysis of data: Ilaria Portarena, Lucia Anemona; Interpretation of data: Buonomo Oreste Claudio; Drafting of article: Materazzo Marco, Gianluca Vanni, Andrea Grasso; Critical revision: Rosaria Meucci, Camilla Deiana, Ljuba Morando.

\section{Acknowledgements}

The study was in part supported by a grant from the Italian Ministry of Health.

\section{References}

1 AIOM (Associazione Italiana Oncologia Medica) - Linee guida NEOPLASIE DELLA MAMMELLA, 2019. Avaible at: https://www.aiom.it/wp-content/uploads/2019/10/2019_LG _AIOM_Mammella.pdf (Last accessed on 3rd December 2019)

2 Del Prete S, Caraglia M, Luce A, Montella L, Galizia G, Sperlongano P, Cennamo G, Lieto E, Capasso E, Fiorentino O, Aliberti M, Auricchio A, Iodice P and Addeo R: Clinical and pathological factors predictive of response to neoadjuvant chemotherapy in breast cancer: A single center experience. Oncol Lett 18: 3873-3879, 2019. PMID: 31516598. DOI: 10.3892/ol.2019.10729

3 Brzezinska $\mathrm{M}$ and Dixon JM: Inflammatory breast cancer: no longer an absolute contraindication for breast conservation surgery following good response to neoadjuvant therapy. Gland Surg 7: 520-524, 2018. PMID: 30687625. DOI: 10.21037/gs.2018.08.04

4 Caldana M, Pellini F, Lombardi D, Mirandola S, Invento A and Pollini GP: Breast cancer and neoadjuvant chemotherapy: indications for and limits of breast-conserving surgery. Ann Ital Chir 89: 392-397, 2018. PMID: 30569900.

5 Golshan M, Cirrincione CT, Sikov WM, Carey LA, Berry DA, Overmoyer B, Henry NL, Somlo G, Port E, Burstein HJ, Hudis C, Winer E, Ollila DW and for the Alliance for Clinical Trials in Oncology: Impact of neoadjuvant therapy on eligibility for and frequency of breast conservation in stage II-III HER2positive breast cancer: surgical results of CALGB 40601 (Alliance). Breast Cancer Res Treat 160: 297-304, 2016. PMID: 27704226. DOI:10.1007/s10549-016-4006-6.

6 Calì Cassi L, Vanni G, Petrella G, Orsaria P, Pistolese C, Lo Russo G, Innocenti M and Buonomo O: Comparative study of oncoplastic versus non-oncoplastic breast conserving surgery in a group of 211 breast cancer patients. Eur Rev Med Pharmacol Sci 20: 2950-2954, 2016. PMID: 27460720.

7 Calì Cassi L, Biffoli F, Francesconi D, Petrella G and Buonomo $\mathrm{O}$ : Anesthesia and analgesia in breast surgery: the benefits of peripheral nerve block. Eur Rev Med Pharmacol Sci 21: 13411345, 2017. PMID: 28387892.

8 Buonomo O, Cabassi A, Guadagni F, Piazza A, Felici A, Piccirillo R, Atzei GP, Cipriani C, Schiaroli S, Mariotti S, Guazzaroni MN, Cossu E, Simonetti G, Pernazza E, Casciani $\mathrm{CU}$ and Roselli M: Radioguided-surgery of early breast lesions. Anticancer Res 21: 2091-2097, 2001. PMID: 11501831.

9 Rastogi P, Anderson SJ, Bear HD, Geyer CE, Kahlenberg MS, Robidoux A, Margolese RG, Hoehn JL, Vogel VG, Dakhil SR, Tamkus D, King KM, Pajon ER, Wright MJ, Robert J, Paik S, Mamounas EP and Wolmark N: Preoperative chemotherapy: Updates of National Surgical Adjuvant Breast and Bowel Project Protocols B-18 and B-27. J Clin Oncol 26: 778-785, 2008. PMID: 18258986. DOI: 10.1200/JCO.2007.15.0235
10 Schott AF and Hayes DF: Defining the benefits of neoadjuvant chemotherapy for breast cancer. J Clin Oncol 30: 1747-1749, 2012. PMID: 22508810. DOI: 10.1200/JCO.2011.41.3161.

11 Ring AE, Smith IE, Ashley S, Fulford LG and Lakhani SR: Oestrogen receptor status, pathological complete response and prognosis in patients receiving neoadjuvant chemotherapy for early breast cancer. Br J Cancer 91: 2012-2017, 2004. PMID: 15558072. DOI: $10.1038 /$ sj.bjc.6602235

12 Gralow JR, Burstein HJ, Wood W, Hortobagyi GN, Gianni L, von Minckwitz G, Buzdar AU, Smith IE, Symmans WF, Singh $\mathrm{B}$ and Winer EP: Preoperative therapy in invasive breast cancer: pathologic assessment and systemic therapy issues in operable disease. J Clin Oncol 26: 814-819, 2008. PMID: 18258991. DOI: $10.1200 / J C O .2007 .15 .3510$

13 Schwartz GF, Hortobagyi GN and Masood S: Proceedings of the consensus conference on neoadjuvant chemotherapy in carcinoma of the breast, April 26-28, 2003. In: Human Pathology. Philadelphia, PA, USA, pp. 781-784, 2004. PMID: 15197792. DOI: $10.1002 /$ cncr.20298

14 Scholl SM, Fourquet A, Asselain B, Pierga JY, Vilcoq JR, Durand JC, Dorval T, Palangié T, Jouve M and Beuzeboc P: Neoadjuvant versus adjuvant chemotherapy in premenopausal patients with tumours considered too large for breast conserving surgery: preliminary results of a randomised trial: S6. Eur J Cancer 30A: 645652, 1994. PMID: 8080680. DOI: 10.1016/0959-8049(94)90537-1

15 Early Breast Cancer Trialists' Collaborative Group (EBCTCG): Long-term outcomes for neoadjuvant versus adjuvant chemotherapy in early breast cancer: meta-analysis of individual patient data from ten randomised trials. Lancet Oncol 19: 27-39, 2018. PMID: 29242041. DOI: 10.1016/S1470-2045(17)30777-5

16 Spring L, Fell G, Arfe A, Trippa L, Greenup R, Reynolds K, Smith B, Moy B, Isakoff S, Parmigiani G and Bardia A: Abstract GS2-03: Pathological complete response after neoadjuvant chemotherapy and impact on breast cancer recurrence and mortality, stratified by breast cancer subtypes and adjuvant chemotherapy usage: Individual patient-level meta-analyses of over 27,000 patients. American Association for Cancer Research (AACR), pp. GS2-03-GS2-03, 2019. DOI: 10.1158/1538-7445

17 LeVasseur N, Sun J, Gondara L, Diocee R, Speers C, Lohrisch $\mathrm{C}$ and Chia S: Impact of pathologic complete response on survival after neoadjuvant chemotherapy in early-stage breast cancer: a population-based analysis. J Cancer Res Clin Oncol, 2019. PMID: 31741041. DOI: 10.1007/s00432-019-03083-y

18 Zhu X, Xue J, Gu X, Chen G, Cao F, Shan H, Wang D, Qiao X, Liu $\mathrm{C}$ and Zhang Y: Neoadjuvant chemotherapy plays an adverse role in the prognosis of grade 2 breast cancer. J Cancer 10: 56615670, 2019. PMID: 31737103. DOI: $10.7150 /$ jca.33168

19 Marzocchella L, Sini V, Buonomo O, Orlandi A, Masuelli L, Bonanno E, Lista F, Turriziani M, Manzari V, Roselli M, Modesti A and Bei R: Spontaneous immunogenicity of ribosomal $\mathrm{P} 0$ protein in patients with benign and malignant breast lesions and delay of mammary tumor growth in P0vaccinated mice. Cancer Sci 102: 509-515, 2011. PMID: 21175994. DOI: $10.1111 / \mathrm{j} .1349-7006.2010 .01814 . x$

20 De Azambuja E, Holmes AP, Piccart-Gebhart M, Holmes E, Di Cosimo S, Swaby RF, Untch M, Jackisch C, Lang I, Smith I, Boyle F, Xu B, Barrios CH, Perez EA, Azim HA, Kim SB, Kuemmel S, Huang CS, Vuylsteke P, Hsieh RK, Gorbunova V, Eniu A, Dreosti L, Tavartkiladze N, Gelber RD, Eidtmann H and Baselga J: Lapatinib with trastuzumab for HER2-positive early 
breast cancer (NeoALTTO): survival outcomes of a randomised, open-label, multicentre, phase 3 trial and their association with pathological complete response. Lancet Oncol 15: 1137-1146, 2014. PMID: 25130998. DOI: 10.1016/S1470-2045(14)70320-1

21 Buonomo OC, Caredda E, Portarena I, Vanni G, Orlandi A, Bagni C, Petrella G, Palombi L and Orsaria P: New insights into the metastatic behavior after breast cancer surgery, according to well-established clinicopathological variables and molecular subtypes. PLoS One 12, 2017. PMID: 28922402. DOI: 10.1371/ journal.pone. 0184680

22 Toss A, Venturelli M, Peterle C, Piacentini F, Cascinu S and Cortesi L: Molecular biomarkers for prediction of targeted therapy response in metastatic breast cancer: Trick or treat? Int J Mol Sci 18, 2017. PMID: 28054957. DOI: 10.3390/ijms 18010085

23 Roselli M, Guadagni F, Buonomo O, Belardi A, Ferroni P, Diodati A, Anselmi D, Cipriani C, Casciani CU, Greiner J and Schlom J: Tumor markers as targets for selective diagnostic and therapeutic procedures. Anticancer Res 16: 2187-2192, 1996. PMID: 8694541.

24 Ferroni P, Roselli M, Spila A, D’Alessandro R, Portarena I, Mariotti S, Palmirotta R, Buonomo O, Petrella G and Guadagni F: Serum sE-selectin levels and carcinoembryonic antigen mRNA-expressing cells in peripheral blood as prognostic factors in colorectal cancer patients. Cancer 116: 2913-2921, 2010. PMID: 20336782. DOI: 10.1002/cncr.25094

25 Ferroni P, Palmirotta R, Spila A, Martini F, Formica V, Portarena I, Del Monte G, Buonomo O, Roselli M and Guadagni F: Prognostic value of carcinoembryonic antigen and vascular endothelial growth factor tumor tissue content in colorectal cancer. Oncology 71: 176184, 2006. PMID: 17652942. DOI: 10.1159/000106072

26 Kaufmann M, Hortobagyi GN, Goldhirsch A, Scholl S, Makris A, Valagussa P, Blohmer JU, Eiermann W, Jackesz R, Jonat W, Lebeau A, Loibl S, Miller W, Seeber S, Semiglazov V, Smith R, Souchon R, Stearns V, Untch M and Von Minckwitz G: Recommendations from an international expert panel on the use of neoadjuvant (primary) systemic treatment of operable breast cancer: An update. J Clin Oncol 24: 1940-1949, 2006. PMID: 16622270. DOI: $10.1200 / J C O .2005 .02 .6187$

27 Sanford RA, Lei X, Barcenas CH, Mittendorf EA, Caudle AS, Valero V, Tripathy D, Giordano SH and Chavez-MacGregor M: Impact of time from completion of neoadjuvant chemotherapy to surgery on survival outcomes in breast cancer patients. Ann Surg Oncol 23: 1515-1521, 2016. PMID: 26678405. DOI: 10.1245/s10434-015-5020-3

28 Peled AW, Wang F, Foster RD, Alvarado M, Ewing CA, Sbitany $\mathrm{H}$ and Esserman LJ: Expanding the indications for total skinsparing mastectomy: Is it safe for patients with locally advanced disease? Ann Surg Oncol 23: 87-91, 2016. PMID: 26170194. DOI: $10.1245 / \mathrm{s} 10434-015-4734-6$

29 Truin W, Vugts G, Roumen RMH, Maaskant-Braat AJG, Nieuwenhuijzen GAP, van der Heiden-van der Loo M, TjanHeijnen VCG and Voogd AC: Differences in response and surgical management with neoadjuvant chemotherapy in invasive lobular versus ductal breast cancer. Ann Surg Oncol 23: 51-57, 2016. PMID: 25980321. DOI: 10.1245/s 10434-015-4603-3

30 Franceschini G, Di Leone A, Natale M, Sanchez MA and Masett R: Conservative surgery after neoadjuvant chemotherapy in patients with operable breast cancer. Ann Ital Chir 89: 290, 2018. PMID: 30352955.

31 Šuk J, Schwarzbacherová I and Kimleová K: Breast conservative surgery after neoadjuvant oncologic treatment for breast carcinoma at the 1st Department of Surgery, 1st Faculty of Medicine of Charles University and General Teaching Hospital in Prague over a ten-year period (2004-2013). Rozhl Chir 96: 432-437, 2017. PMID: 29308910.

32 Chan BKY, Wiseberg-Firtell JA, Jois RHS, Jensen K and Audisio RA: Localization techniques for guided surgical excision of nonpalpable breast lesions. Cochrane Database Syst Rev 2015, 2015. PMID: 26718728. DOI: 10.1002/14651858.CD009206.pub2

33 Buonomo O, Granai A V, Felici A, Piccirillo R, De Liguori Carino N, Guadagni F, Polzoni M, Mariotti S, Cipriani C, Simonetti G, Cossu E, Schiaroli S, Altomare V, Cabassi A, Pernazza E, Casciani $\mathrm{CU}$ and Roselli M: Day-surgical management of ductal carcinoma in situ (DCIS) of the breast using wide local excision with sentinel node biopsy. Tumori 88: S48-49, 2002. PMID: 12365390.

34 Mangone L, Mancuso P, Tagliabue G, Filiberti RA, Carrozzi G, Iacovacci S, Mazzucco W, Tumino R, Minicozzi P, Sant M and Giorgi Rossi P: Neoadjuvant therapy for breast cancer. Tumori J: 030089161986950, 2019. PMID: 31496430. DOI: $10.1177 / 0300891619869505$

35 Heitz F, Kümmel S, Lederer B, Solbach C, Engels K, Ataseven B, Sinn B, Blohmer JU, Denkert C, Barinoff J, Fisseler-Eckhoff $A$ and Loibl S: Impact of nuclear oestrogen receptor beta expression in breast cancer patients undergoing neoadjuvant chemotherapy. Geburtshilfe Frauenheilkd 79: 1110-1117, 2019. PMID: 31656321. DOI: 10.1055/a-0987-9898

36 Li F, Ma L, Geng C, Liu C, Deng H, Yue M, Ding Y, Wang X and Liu Y: Analysis of the relevance between molecular subtypes and efficacy of neoadjuvant chemotherapy in breast cancer as well as its prognostic factors. Pathol Res Pract 214: 1166-1172, 2018. PMID: 29945816. DOI: 10.1016/j.prp.2018.06.010

37 Dong JM, Wang HX, Zhong XF, Xu K, Bian J, Feng Y, Chen L, Zhang L, Wang X, Ma DJ and Wang B: Changes in background parenchymal enhancement in HER2-positive breast cancer before and after neoadjuvant chemotherapy: Association with pathologic complete response. Med (United States) 97, 2018. PMID: 30412117. DOI: 10.1097/MD.0000000000012965

38 Li F, Ma L, Geng C, Liu C, Deng H, Yue M, Ding Y, Wang X and Liu Y: Analysis of the relevance between molecular subtypes and efficacy of neoadjuvant chemotherapy in breast cancer as well as its prognostic factors. Pathol Res Pract 214: 1166-1172, 2018. PMID: 29945816. DOI: 10.1016/j.prp.2018.06.010

39 Schillaci O, Cossu E, Buonomo O, Granai A V, Pistolese CA, Danieli R, Simonetti G, Coover LR and Kuhn PJ: Dedicated breast camera: is it the best option for scintimammography? J Nucl Med 46: 550; author reply 551, 2005. PMID: 15750173.

40 Orsaria P, Chiaravalloti A, Caredda E, Marchese PV, Titka B, Anemona L, Portarena I, Schillaci O, Petrella G, Palombi L and Buonomo OC: Evaluation of the usefulness of FDG-PET/CT for nodal staging of breast cancer. Anticancer Res 38: 6639-6652, 2018. PMID: 30504372. DOI: 10.21873/anticanres.13031

41 Orsaria P, Chiaravalloti A, Fiorentini A, Pistolese C, Vanni G, Granai AV, Varvaras D, Danieli R, Schillaci O, Petrella G and Buonomo OC: PET Probe-guided surgery in patients with breast cancer: Proposal for a methodological approach. In Vivo (Brooklyn) 31: 101-110, 2017. PMID: 28064227. DOI: 10.21873/invivo.11031

Received November 29, 2019

Revised December 4, 2019

Accepted December 6, 2019 